\title{
Cost effectiveness analysis of hyperbaric therapy in osteoradionecrosis
}

\author{
James Dempsey MBA, Nick Hynes MSc MD, Teresa Smith MBA RRT CHT, Janet E Sproat MSc MD FRCSC \\ Hamilton Civic Hospitals, Hamilton, Ontario
}

\begin{abstract}
J Dempsey, N Hynes, T Smith, JE Sproat. Cost effectiveness analysis of hyperbaric therapy in osteoradionecrosis. Can J Plast Surg 1997;5(4):221-229. In this time of fiscal restraint it is important to consider the costs and effectiveness of the treatments used whenever more than one treatment option is available. This paper presents an economic evaluation undertaken from a societal perspective to determine the cost effectiveness of using a modified hyperbaric oxygen (HBO) protocol to treat osteoradionecrosis of the mandible. Costs for the study group were obtained from a retrospective study of 21 patients who underwent a modified HBO protocol at the Hamilton Civic Hospitals, Hamilton, Ontario - a tertiary centre. A hypothetical control group was created and matched to the study group. Costs for this hypothetical conservative therapy group were calculated based on expected outcomes obtained from the literature. A sensitivity analysis was performed to determine the sensitivity to changes in the assumptions that were made and the data that were obtained from the literature. The modified HBO protocol was both less expensive and more effective than conservative therapy and, thus, demonstrated dominance. The number of days that each patient spends in the hospital is the key cost driver for conservative therapy treatment for osteoradionecrosis of the mandible. Patients who underwent the modified HBO protocol enjoyed greater pain reduction and increased sleep while requiring fewer narcotics.
\end{abstract}

Key Words: Hyperbaric oxygen, Mandible, Osteoradionecrosis

\section{Analyse coût-efficacité du traitement hyperbare dans l'ostéoradionécrose}

RÉSUMÉ : En cette époque de restrictions budgétaires, il est important de songer au coût et à l'efficacité des traitements utilisés dès que plus d'un choix thérapeutique sont offerts. Cet article présente une évaluation économique entreprise d'un point de vue sociétal afin de mesurer le rapport coût-efficacité de l'utilisation d'un protocole modifié d'oxygène hyperbare (OHB) pour traiter l'ostéoradionécrose du mandibule. Les coûts pour le groupe étudié ont été obtenus à partir d'une étude rétrospective de 21 patients qui ont subi le protocole modifié OHB aux Hamilton Civic Hospitals de Hamilton, en Ontario, un centre de soins tertiaires. Un groupe-témoin hypothétique a été créé et assorti au groupe étudié. Les coûts de ce traitement conservateur hypothétique ont été calculés à partir des résultats prévus obtenus dans la littérature. Une analyse de sensibilité a été effectuée afin de déterminer la sensibilité aux changements des hypothèses qui ont été formulées et des données obtenues dans la littérature. Le protocole modifié OHB s'est révélé moins coûteux et plus efficace que le traitement conservateur et a ainsi dominé. Le nombre de jours que chaque patient a passé dans les hôpitaux est le principal élément générateur de coût dans le traitement conservateur de l'ostéoradionécrose du mandibule. Les patients qui ont subi le protocole modifié ont été mieux soulagés, ont mieux dormi et ont eu besoin d'un moins grand nombre de narcotiques.

A proportion of patients who undergo irradiation of malignant lesions in the head and neck experience healthy tissue breakdown or osteoradionecrosis. Osteoradionecrosis is exposed bone in a field of irradiation that has failed to heal for at least six months (1). Although a wide range has been reported, the incidence of osteoradionecrosis in the mandible after irradiation of the head and neck region averages about $18 \%$ (2). The conventional treatment of osteoradionecrosis of the mandible, known as 'conservative treatment', includes

Correspondence: Dr Janet E Sproat, Burn Trauma Unit, Hamilton Civic Hospitals General Division, 237 Barton Street East, Hamilton, Ontario L8L 2X2. Telephone 905-527-4322 ext 6350, fax 905-527-1941 avoidance of local irritants, irrigation with a wide variety of agents, antibiotic therapy and superficial sequestrectomies (3). If this course of treatment does not resolve the disease, reconstructive surgery is required.

The Marx University of Miami hyperbaric oxygen (HBO) protocol is an alternative for the treatment of osteoradionecrosis. This treatment combines HBO with specific surgeries, when indicated, and is based on the pathophysiology of radiation leading to hypovascular, hypocellular, hypoxic tissue (1). The purpose of this study was to conduct an analysis comparing the incremental costs and effects of a modified HBO protocol with the conservative treatment of osteoradionecrosis of the mandible. 


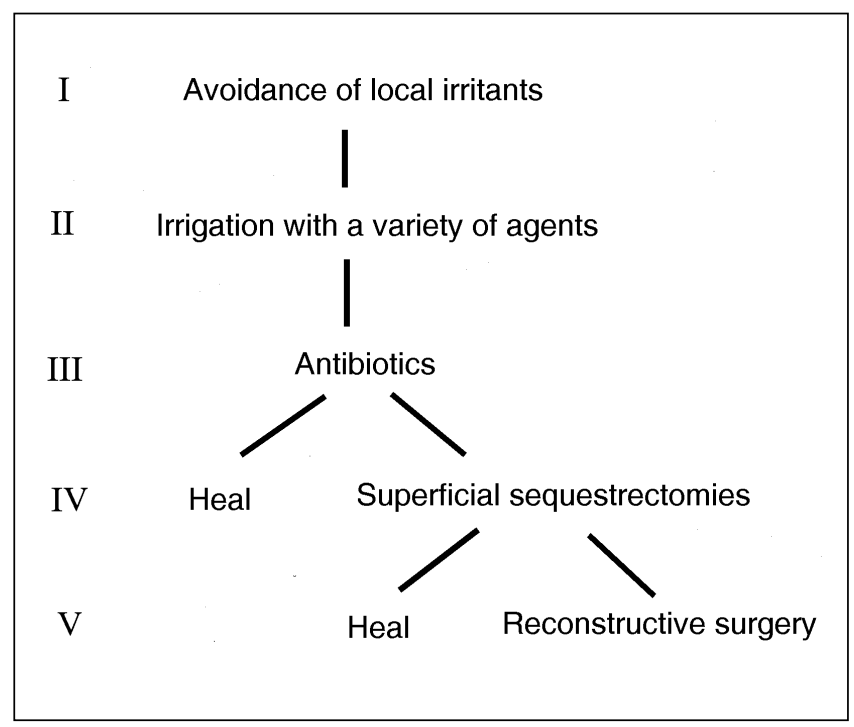

Figure 1) Flow chart representing a patient's journey through conservative therapy. Adapted from reference 3

The pathogenesis of osteoradionecrosis was originally thought to be radiation followed by trauma resulting in infection. Meyer (4) summarized the original pathogenesis theory as follows. Radiation causes a thickening of the intima lining of the blood vessels, which often results in thrombosis in the inferior alveolar artery. Trauma may result from the extraction of teeth after radiation has been completed, or even from injury to the mucoperiosteum of the mandible under dentures. In the past, when teeth were extracted as a preradiation procedure with failure to do an alveolectomy to eliminate all sharp edges of septal and cortical bone, the bony edges pierced through the mucosa, and these openings acted as a passage to permit the entrance of oral bacteria flora into the underlying bone. This infection made rapid progress in the irradiated bone, which had lost its resistance to bacteria. The infection then proceeded to extensive, painful necrosis of the bone, often accompanied by sloughing of the oral and facial soft tissues. Along with this concept of the pathophysiology of osteoradionecrosis, it has been suggested that seven factors contribute to its development. These factors include the size of the tumour, combined interstitial and external beam radiation, energy of the radiation source, field size and number of treatment fields, oral hygiene, dental trauma and/or dental extractions and, finally, postradiotherapy radical neck dissection (3).

Marx (5) proposed an alternative pathogenesis in which microorganisms play a very minor role. According to Marx, radiation produces hypovascular, hypocellular, hypoxic tissue in which the ability to replace normal collagen loss or normal cellular loss is severely compromised or nonexistent. Once any wound is created, effective healing cannot occur due to the increased demands for oxygen, energy and nutrition in a tissue that cannot maintain itself at its former level of metabolic demand. Thus, osteoradionecrosis is actually a problem of wound healing rather than infection. Marx suggested that radiation leads to tissue breakdown, collagen lysis and cellular death exceeding synthesis and cellular replication, which ultimately results in chronic nonhealing wounds in which energy, oxygen and structural precursor demands exceed supply. In many patients osteoradionecrosis results in continuous pain, narcotic addiction and a tremendous loss of time from both the family and workplace (1).

\section{TREATMENT OPTIONS}

Conservative therapy: The standard of care for osteoradionecrosis of the jaws throughout the 1950s, 1960s and much of the 1970s was conservative therapy. Figure 1 represents a patient's journey through conservative therapy as summarized by Rankow and Weissman (3). This approach involves avoidance of local irritants such as very hot, spicy, acidic or cold foods, and alcohol and cigarette smoke. It is often difficult to obtain patient compliance with respect to the required lifestyle changes associated with cessation of alcohol or cigarette use. The second step requires the patient to irrigate the disease site with anything from mouthwash to saline solutions to hydrogen peroxide to combat potential infections. Medication plays a large role in this course of treatment. Antibiotics are used to combat infections, and analgesics are used to treat the pain that patients experience with the disease. If healing does not occur after the patient has followed this regimen for a period of time, a number of superficial sequestrectomies are performed to remove the necrotic tissue. According to the literature, the resolution rate after the first four steps of this therapy ranges from $8 \%$ (5) to $75 \%$ (6), with a number of other authors reporting different rates within this range $(3,7)$. If the patient does not heal after the first four steps, reconstructive surgery is required. However, even reconstructive surgery is not guaranteed to result in resolution of the disease - it has a reported success rate of $66 \%$ (8). In some cases patients will bounce back and forth between the steps of conservative therapy for a number of years without resolution of osteoradionecrosis.

In the mid-1970s, reports of the benefits of HBO began to appear in the literature. Claims that pathological fractures would unite without surgery, that fibrous unions would unite without bone grafts and that orocutaneous fistulae would heal with HBO alone were reported $(9,10)$. According to Marx (11), "The single most important reason nonsurgical and conservative surgical approaches are associated with such statistically poor results is that they fail to address the basic pathophysiology of the disease". The introduction of hyperbaric therapy in the treatment of osteoradionecrosis along with an alternative proposal for the pathogenesis of osteoradionecrosis led to the establishment of the Marx University of Miami protocol.

Marx University of Miami protocol: The Marx University of Miami protocol combines HBO with specific surgeries, when indicated, and is based on the pathogenesis of radiation leading to hypocellular, hypovascular, hypoxic tissue. Although exposure to $\mathrm{HBO}$ often resolves the disease process, in all cases where the bone must be resected, the angiogenesis and fibroplasia resulting from exposure to $\mathrm{HBO}$ have 
already prepared the recipient tissue bed to support full bony reconstruction (1). Marx et al (12) reported an osteoradionecrosis resolution rate of $100 \%$ when this protocol is followed. Figure 2 illustrates the pathways through the Marx University of Miami protocol. With the exception of patients presenting with orocutaneous fistulae, pathological fracture or extensive bone resorption (who receive $30 \mathrm{HBO}$ exposures and then enter stage III), all patients with osteoradionecrosis enter stage I. During stage I each patient receives $30 \mathrm{HBO}$ exposures (dives) at 2.4 atmospheres absolute for 90 mins each. Wound care is maintained with saline rinses, and antibiotics are discontinued. If the wound shows definitive clinical improvement after 30 dives the patient completes 10 more dives to achieve full mucosal cover. However, if there is no definitive improvement after 30 dives, the patient is identified as a nonresponder to stage I and advances to stage II. During stage II a local surgical debridement is attempted to identify patients with only cortical or superficial bone involvement who can be resolved before jaw resection. If healing progresses without complication the patient undergoes 10 more dives. However, if the wound dehisces leaving exposed, nonhealing bone, the patient is identified as a nonresponder to stage II and advances to stage III.

Stage III involves a partial jaw resection and 10 additional dives in the hyperbaric chamber. Upon completion of stage III the patient enters stage III-R in which bony reconstruction is accomplished from a transcutaneous approach without oral contamination. Ten postreconstructive surgery dives are completed, and jaw fixation is maintained for eight weeks. If further surgery is not required the patient may enter prosthetic rehabilitation one month after fixation is released.

In this study the HBO protocol was modified so that the treating physician could use his or her discretion to determine the number of dives that the patient would undergo at each stage of the protocol, ie, if a wound showed significant healing, the protocol was stopped. For example, a number of patients only underwent 20 dives in the hyperbaric chamber during the course of their treatment.

Both conservative therapy and the $\mathrm{HBO}$ protocol have the resolution of osteoradionecrosis as their one, unambiguous objective. However, both the costs associated with each treatment method and their reported effectiveness differ. Probabilities for healing are shown in Figure 3.

\section{METHODS AND MATERIALS}

The question addressed in this study was, "From a societal perspective, is a modified HBO protocol a more cost effective method of treating patients with osteoradionecrosis than conservative therapy?".

The costs associated with 21 patients who underwent a modified HBO protocol at the Hamilton Civic Hospitals, Hamilton, Ontario for the treatment of osteoradionecrosis were collected. This group was compared with a hypothetical group of 21 patients with the same demographics (Table 1) who would hypothetically undergo conservative therapy for the same disease. Costs for the hypothetical group were calculated based on expected outcomes taken from the literature.

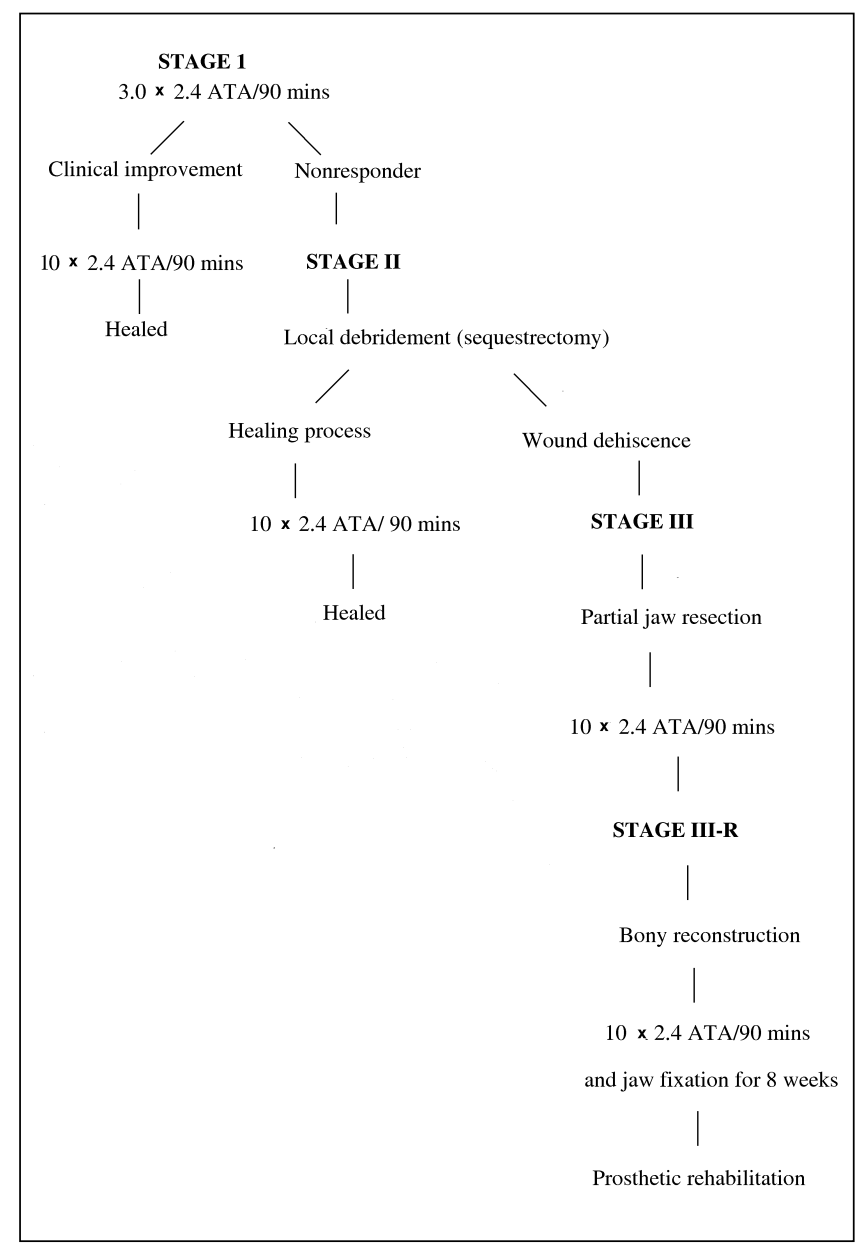

Figure 2) Pathways through the Marx University of Miama protocol. ATA Atmospheres absolute

The data used in this study were obtained from two sources. Primary data were obtained from the Hamilton Civic Hospitals, Hamilton, Ontario, and secondary data were derived from the available literature.

A number of costs needed to be calculated for this study including the costs of medications, sequestrectomies, dental extractions, out-patient visits, hyperbaric therapy, in-patient days and reconstructive surgery (Tables 2,3). All costs are given in 1995 Canadian dollars.

Medication: The amount and type of medication consumed by the average conservative therapy patient, as found by Rankow and Weissman (3) and reported in Davis and Hunt (1), were used to calculate the medication costs for those patients undergoing conservative therapy. Because patients undergoing the HBO protocol had been taken off of most of their medications by their 10th dive in the hyperbaric chamber, their medication costs were prorated accordingly.

Sequestrectomy: In calculating the cost of a sequestrectomy, only the oral surgery consult and exam, and sequestrectomy procedure costs were included. 
TABLE 1: Patient demographics for hyperbaric oxygen (HBO) protocol groups

\begin{tabular}{|c|c|c|c|c|c|c|c|c|}
\hline 1 & $\mathrm{~F}$ & 53 & I & II & 4500 & 30 & 2 & - \\
\hline 3 & $F$ & 85 & I & 1 & 6774 & 20 & - & - \\
\hline 4 & $M$ & 49 & I & II & 6600 & 19 & 1 & - \\
\hline 6 & $M$ & 58 & 1 & II & 6000 & 49 & 2 & 1 \\
\hline 7 & $M$ & 74 & I & 1 & $5500 / 2400$ & 20 & - & - \\
\hline 8 & $M$ & 42 & II & III-R & 8000 & 40 & - & - \\
\hline 9 & $\mathrm{~F}$ & 51 & I & 1 & 5500 & 20 & - & - \\
\hline 10 & M & 64 & I & 1 & 1000 & 20 & 1 & - \\
\hline 14 & M & 57 & 1 & II & - & 20 & - & - \\
\hline 15 & $\mathrm{~F}$ & 67 & II & II & 6000 & 20 & - & - \\
\hline 16 & M & 42 & 1 & 1 & - & 20 & - & - \\
\hline 17 & M & 56 & I & 1 & 6000 & 20 & - & - \\
\hline 18 & $M$ & 43 & II & III-R & 5000 & 20 & - & 1 \\
\hline 19 & $\mathrm{~F}$ & 85 & I & 1 & 6000 & 20 & - & - \\
\hline 20 & M & 64 & 1 & 1 & 3600 & 20 & - & - \\
\hline 21 & $\mathrm{~F}$ & 66 & 1 & 1 & 5000 & 20 & - & - \\
\hline Totals & $8 \mathrm{~F}, 3 \mathrm{M}$ & 59 & 17-I, 4-II & 12-I, 7-II, 2-III & 4515 & 530 & 9 & 2 \\
\hline
\end{tabular}

F Female; M Male; Reconstr Reconstruction; Seq Sequestrectomies

Dental extractions: Forty teeth were extracted from the modified HBO protocol patients. This number was matched for the conservative treatment group. When determining costs, only the extraction fee was included.

Out-patient visit fee: The out-patient visit fee was provided by the hospital and represented overhead such as general and nursing administration, finance, materials management, health records, housekeeping, admitting, plant operation and maintenance, depreciation, interest expense and bad debt expense.

\section{Hyperbaric therapy}

Capital costs: Capital costs of hyperbaric therapy include the purchase of the required equipment; renovations to the hospital that were required to house the hyperbaric unit, staff education and development; and the opportunity cost of the land. Because the equipment was purchased in 1992, the original cost was indexed to 1995 dollars and amortized over the useful life of the asset to incorporate depreciation, and the opportunity cost of capital using the Canadian standard discount rate of 5\%. Table 3 outlines these costs.

Renovations to the hospital that were required to house the hyperbaric unit were amortized over 20 years. Initial staff education and development were considered a capital cost and were amortized over five years. Finally, the opportunity cost of the land was determined according to a rental cost per square foot of developed land quote from the Metro Toronto Real Estate Board and was consequently an overestimate. However, information was not readily available for the Hamilton area.

Operational costs: Operational costs represented the resources consumed per patient dive with respect to salaries, preventive maintenance, laundry, administration, supplies and the standard out-patient visit fee. The salary cost included a $13 \%$ benefits package and reflected the time that the chamber operator spent with the patient during the dive. Preventive maintenance was performed daily, weekly, monthly and biannually, and again the serviceperson's salary was adjusted to include a $13 \%$ benefits package. During each dive the patient used a cotton gown, pillowcase and sheet. These items were weighed and multiplied by the standard laundry cost per kilogram. Administrative cost information was provided by the hospital. Resources were also put aside for yearly continuing education and were included in the operating costs. Supply costs were obtained from the monthly supply budget for the hyperbaric unit. It was assumed that all patients consumed the same amount of supplies. The cost of oxygen per dive was also determined. Finally, the out-patient visit fee was provided by the hospital and was addressed in the previous subsection. 
TABLE 2: Cost per product or service (conservative therapy)

\begin{tabular}{|c|c|c|c|}
\hline Item & Price & $\begin{array}{c}\text { Amount/ } \\
\text { patient }(g)^{\star}\end{array}$ & $\begin{array}{c}\text { Cost/ } \\
\text { patient }\end{array}$ \\
\hline \multicolumn{4}{|l|}{ Medications } \\
\hline Penicillin & $\$ 0.03 / 300 \mathrm{mg}$ & 532 & $\$ 53.20$ \\
\hline Tetracyclene & $\$ 0.01 / 250 \mathrm{mg}$ & 216 & $\$ 8.64$ \\
\hline $\begin{array}{l}\text { Tylenol } 3 \\
\text { (Janssen-Ortho) }\end{array}$ & $\$ 0.05 / 30 \mathrm{mg}$ & 35 & $\$ 58.33$ \\
\hline Oxycodone & $\$ 0.10 / 5 \mathrm{mg}$ & 21 & $\$ 420.00$ \\
\hline Total & & & $\$ 540.17$ \\
\hline \multicolumn{4}{|c|}{ Sequestrectomy (local debridement) } \\
\hline $\begin{array}{l}\text { Oral surgery consult } \\
\text { and examination }\end{array}$ & $\$ 91.00$ & & \\
\hline Sequestrectomy & $\$ 120.00$ & & \\
\hline Total & $\$ 211.00$ & & \\
\hline \multicolumn{4}{|l|}{ Dental extractions } \\
\hline First tooth & $\$ 51.00$ & & \\
\hline $\begin{array}{l}\text { Additional extraction } \\
\text { (same visit) }\end{array}$ & $\$ 25.00$ & & \\
\hline Total & $\$ 76.00$ & & \\
\hline \multicolumn{4}{|l|}{ Out-patient visits $^{\dagger}$} \\
\hline Out-patient fee & $\$ 58.00$ & & \\
\hline Transportation $^{\ddagger}$ & $\$ 14.63$ & & \\
\hline Total & $\$ 72.63$ & & \\
\hline \multicolumn{4}{|l|}{ In-patient days } \\
\hline Cost per day ${ }^{\S}$ & $\$ 800.00$ & & \\
\hline Total & $\$ 800.00$ & & \\
\hline \multicolumn{4}{|l|}{ Reconstructive surgery" } \\
\hline Surgery & $\$ 2,411.58$ & & \\
\hline Assistant & $\$ 593.72$ & & \\
\hline Anesthesia & $\$ 684.92$ & & \\
\hline Hospital stay & $\$ 5,600.00$ & & \\
\hline $\begin{array}{l}\text { Home care } \\
\text { nursing (one week) }\end{array}$ & $\$ 322.84$ & & \\
\hline Total & $\$ 9,613.06$ & & \\
\hline
\end{tabular}

All costs are in 1995 Canadian dollars. *Adapted from Davis and Hunt (1); ${ }^{\dagger}$ Does not include Ontario Health Insurance Plan fee; ${ }^{\ddagger}$ Average cost per patient; ${ }^{\mathcal{P}}$ Provided by hospital; ${ }^{9}$ Does not include capital costs

Ontario Health Insurance Plan fees: Ontario Health Insurance Plan (OHIP) fees were obtained from the 1995 OHIP Schedule of Benefits (13) and represented the professional fees for the time spent with the patient during the dive and the professional fee for the out-patient visit.

Patient costs: Transportation and parking expenses were calculated for each patient's visit to the hospital based on their place of residence according to the following schedule: $\$ 0.30 / \mathrm{km}$ travelled and $\$ 2.00$ for parking each trip.

In-patient days: The cost of an in-patient day was provided by the hospital and was calculated by dividing the hospital costs for one year by the number of in-patient days for that
TABLE 3: Cost per product or service (hyperbaric oxygen protocol)

\begin{tabular}{|c|c|c|c|}
\hline Item & Price & $\begin{array}{l}\text { Amount/ } \\
\text { patient (g) }\end{array}$ & $\begin{array}{c}\text { Cost/ } \\
\text { patient }\end{array}$ \\
\hline \multicolumn{4}{|l|}{ Medications } \\
\hline Penicillin & $\$ 0.03 / 300 \mathrm{mg}$ & 350 & $\$ 35.00$ \\
\hline Tetracyclene & $\$ 0.01 / 250 \mathrm{mg}$ & 216 & $\$ 8.64$ \\
\hline $\begin{array}{l}\text { Tylenol } 3 \\
\text { (Janssen-Ortho) }\end{array}$ & $\$ 0.05 / 30 \mathrm{mg}$ & 7 & $\$ 11.67$ \\
\hline Oxycodone & $\$ 0.10 / 5 \mathrm{mg}$ & 4.2 & $\$ 84.00$ \\
\hline Total & & & $\$ 139.31$ \\
\hline \multicolumn{4}{|c|}{ Sequestrectomy (local debridement) } \\
\hline $\begin{array}{l}\text { Oral surgery consult } \\
\text { and examination }\end{array}$ & $\$ 91.00$ & & \\
\hline Sequestrectomy & $\$ 120.00$ & & \\
\hline Total & $\$ 211.00$ & & \\
\hline \multicolumn{4}{|l|}{ Dental extractions } \\
\hline First tooth & $\$ 51.00$ & & \\
\hline $\begin{array}{l}\text { Additional extraction } \\
\text { (same visit) }\end{array}$ & $\$ 25.00$ & & \\
\hline Total & $\$ 76.00$ & & \\
\hline \multicolumn{4}{|l|}{ Hyperbaric therapy ${ }^{\dagger}$} \\
\hline $\begin{array}{l}\text { One dive in the } \\
\text { chamber }\end{array}$ & $\$ 350.59$ & & \\
\hline Total & $\$ 350.59$ & & \\
\hline \multicolumn{4}{|l|}{ Reconstructive surgery } \\
\hline Surgery & $\$ 2,411.58$ & & \\
\hline Assistant & $\$ 593.72$ & & \\
\hline Anesthesia & $\$ 684.92$ & & \\
\hline Hospital stay & $\$ 5,600.00$ & & \\
\hline $\begin{array}{l}\text { Home care nursing } \\
\text { (one week) }\end{array}$ & $\$ 322.84$ & & \\
\hline Total & $\$ 9,613.06$ & & \\
\hline
\end{tabular}

All costs are in 1995 Canadian dollars. ${ }^{\star}$ Prorated; ${ }^{\dagger}$ Cost breakdown provided in Table 4

year. It assumed that each patient consumed the same amount of resources and is, thus, subject to criticisms of validity.

Reconstructive surgery: The reconstructive surgery cost represents the surgical fee, assistant's fee, anesthetic fee, hospital stay and one week of home care nursing.

\section{RESULTS}

Outcomes: In the modified HBO protocol group, $57 \%$ of patients healed during stage I, 34\% healed during stage II and the remaining 9\% healed during stage III (Table 1). Outcomes for the hypothetical group undergoing conservative therapy were taken from the literature. From these expected values, 


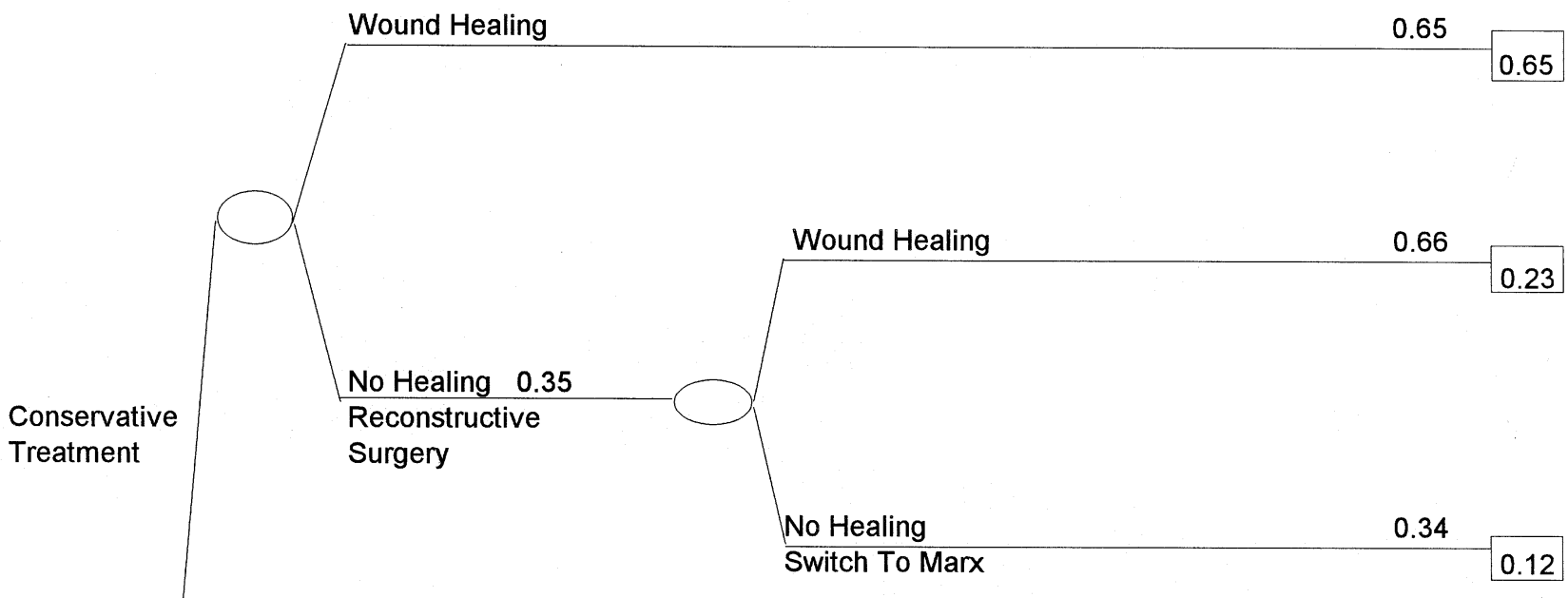

Marx HBO Protocol

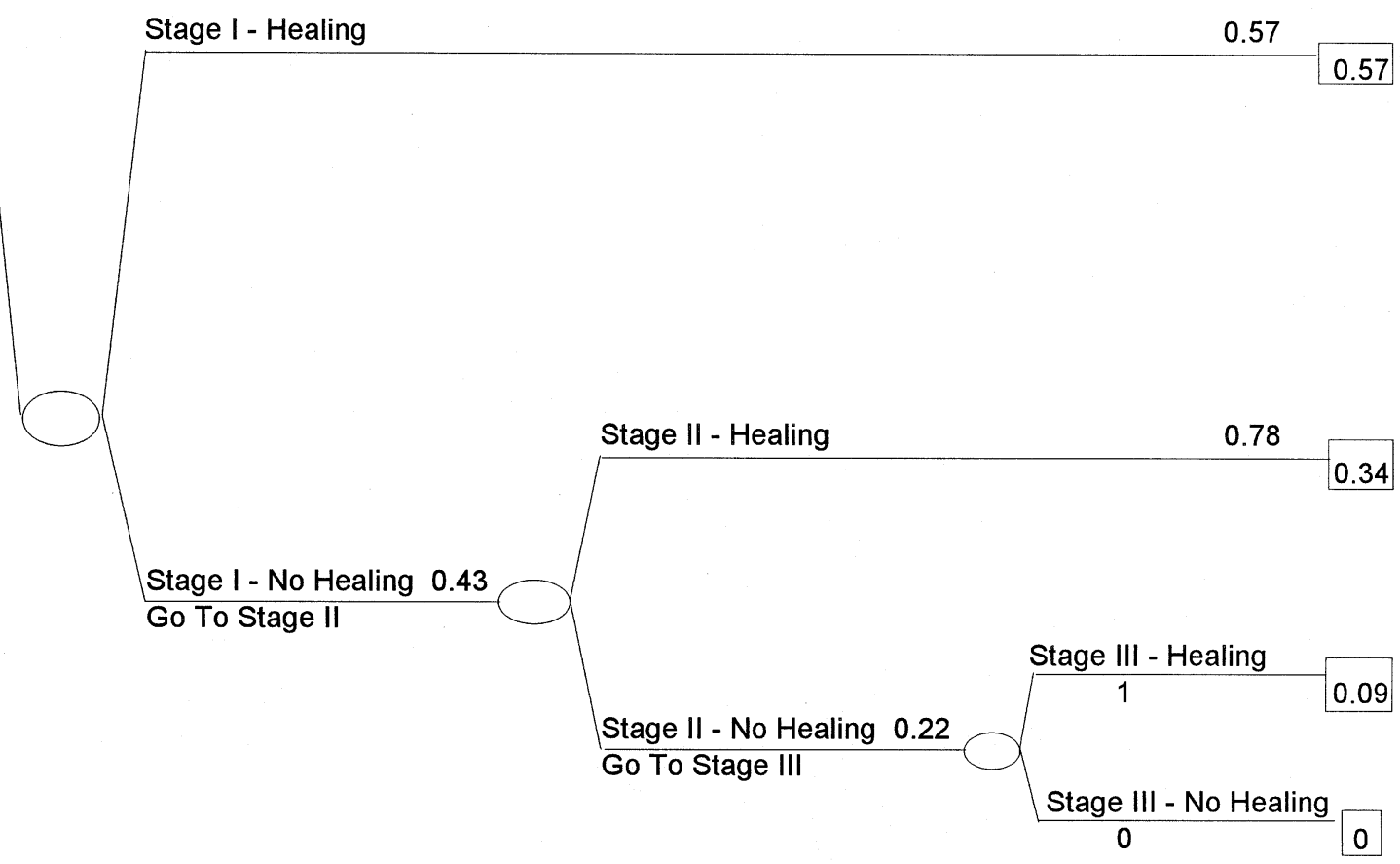

Figure 3) Treatment decision tree with probability of healing. HBO Hyperbaric oxygen; ORN Osteoradionecrosis

$65 \%$ of patients would heal before reconstructive surgery, $23 \%$ would heal after reconstructive surgery and $12 \%$ would not have their disease resolved. Because the expected values reported in the literature varied over a very large range ( $8 \%$ to $75 \%$ ), a sensitivity analysis was performed to determine the outcomes if alternative expected values were used.
Costs: Tables 5 and 6 outline the total costs for the 21 hypothetical patients undergoing conservative therapy and the 21 patients who actually underwent the modified HBO protocol. The total cost to treat the 21 hypothetical patients was found to be $\$ 1,327,444$. This worked out to be an average of $\$ 63,211$ per patient. The total cost of treating the 21 modified HBO 
protocol patients was $\$ 211,362$, and the average cost per patient was $\$ 10,064$.

The osteoradionecrosis of the 21 patients treated according to the modified HBO protocol resolved. By using expected outcomes from the literature, it was determined that 18 of the 21 hypothetical patients would resolve their disease under conservative therapy. To calculate the total costs of conservative therapy, the average per patient cost of one round of the modified HBO protocol was added to the costs of the three patients who would not have healed under conservative therapy because it was assumed that one round of the HBO protocol would lead to resolution of their disease.

Because, for the group of patients studied, the total cost of the modified HBO protocol was less expensive and three more cases were resolved than with conservative therapy, it can be said that the modified HBO protocol exhibits dominance.

Sensitivity analysis: This study used expected outcomes from the literature and data provided by the hospital, such as the average cost of an in-patient day, which may be subject to criticisms of validity. A sensitivity analysis was performed to address these concerns (Table 7) (14).

\section{DISCUSSION}

In this study, data from actual patients were collected in a retrospective manner and data for the hypothetical group of patients were derived from the literature. A randomized prospective study in which detailed patient-specific information
TABLE 4: Hyperbaric therapy - Cost per dive

\begin{tabular}{lr} 
Capital cost per dive & $\$ 68.31$ \\
Operational cost per dive & $\$ 138.96$ \\
Fees charged to Ontario Health Insurance & $\$ 128.69$ \\
$\quad$ Plan per dive & \\
Patient costs per dive & $\$ 14.63$ \\
Total cost per dive & $\$ 350.59$ \\
\hline
\end{tabular}

All costs are in 1995 Canadian dollars

relating outcomes, side-effects and resource utilization was not completed because it would contravene the current standard of practice. It was necessary to make a number of assumptions in this study. Because assumptions may reduce the validity and reliability of the information presented and the stated conclusions, a sensitivity analysis was conducted to determine how different assumptions would affect the results.

The number of days that each patient spends in the hospital is the key cost driver for the treatment of osteoradionecrosis of the mandible (Table 7). It should also be noted that the cost of the HBO protocol would be the same as that for conservative therapy if each conservative therapy patient only spent an average of 1.57 days in the hospital or if the cost of a one-day stay in the hospital was only $\$ 18.43$.

Patient costs with respect to lost earnings were not included in this analysis for a number of reasons. Because, on average, conservative therapy patients require as many

TABLE 5: Conservative therapy - Total costs for 21 hypothetical patients

\begin{tabular}{|c|c|c|c|c|c|}
\hline Patient(s) & Product or service & $\begin{array}{l}\text { Cost per product } \\
\text { or service (\$) }\end{array}$ & $\begin{array}{l}\text { Number of products } \\
\text { or services per patient }\end{array}$ & Cost per patient & Cost for patient group \\
\hline \multirow[t]{3}{*}{ One to 13} & Medication & 540.17 & 1 & 540.17 & $7,022.21$ \\
\hline & Dental extractions & 76.00 & 1 & 76.00 & 988.00 \\
\hline & Out-patient visits & 72.63 & 31 & $2,251.53$ & $29,269.89$ \\
\hline \multirow[t]{4}{*}{14 to 18} & Medications & 540.17 & 1 & 540.17 & $2,700.85$ \\
\hline & Sequestrectomy & 211.00 & 4 & 844.00 & $4,220.00$ \\
\hline & Dental extractions & 76.00 & 1 & 76.00 & 380.00 \\
\hline & Out-patient visits & 72.63 & 31 & $2,251.53$ & $11,257.65$ \\
\hline 19 to 21 & $\begin{array}{l}\text { Average cost of one } \\
\text { round of Marx } \\
\text { University of Miami } \\
\text { therapy }\end{array}$ & $10,064.87$ & 1 & $10,064.87$ & $30,194.61$ \\
\hline Subtotal & & & & $77,789.63$ & $233,368.89$ \\
\hline Total & & & & & $1,327,444.79$ \\
\hline
\end{tabular}

All costs are in 1995 Canadian dollars. Average cost per patient equals $\$ 63,211.66$ 
TABLE 6: Modified hyperbaric oxygen protocol - Costs for 21 actual patients

\begin{tabular}{lccc}
\hline Product or service & $\begin{array}{c}\text { Cost per product } \\
\text { or service }\end{array}$ & $\begin{array}{c}\text { Number of products } \\
\text { or services }\end{array}$ & $\begin{array}{c}\text { Total cost of product } \\
\text { or service (\$) }\end{array}$ \\
\hline Medication & $\$ 138.31$ & 21 & $2,904.51$ \\
Sequestrectomy & $\$ 211.00$ & 9 & $1,899.00$ \\
Dental extractions & $\$ 76.00$ & 20 & $1,520.00$ \\
Hyperbaric therapy & $\$ 350.59$ & 530 & $185,812.70$ \\
Reconstructive surgery & $\$ 9,613.06$ & 2 & $19,226.12$ \\
Total & & & $211,362.33$ \\
\hline
\end{tabular}

All costs are in 1995 Canadian dollars and were calculated from reference 13. Average cost per patient equals \$10,172.64

TABLE 7: Sensitivity analysis summary

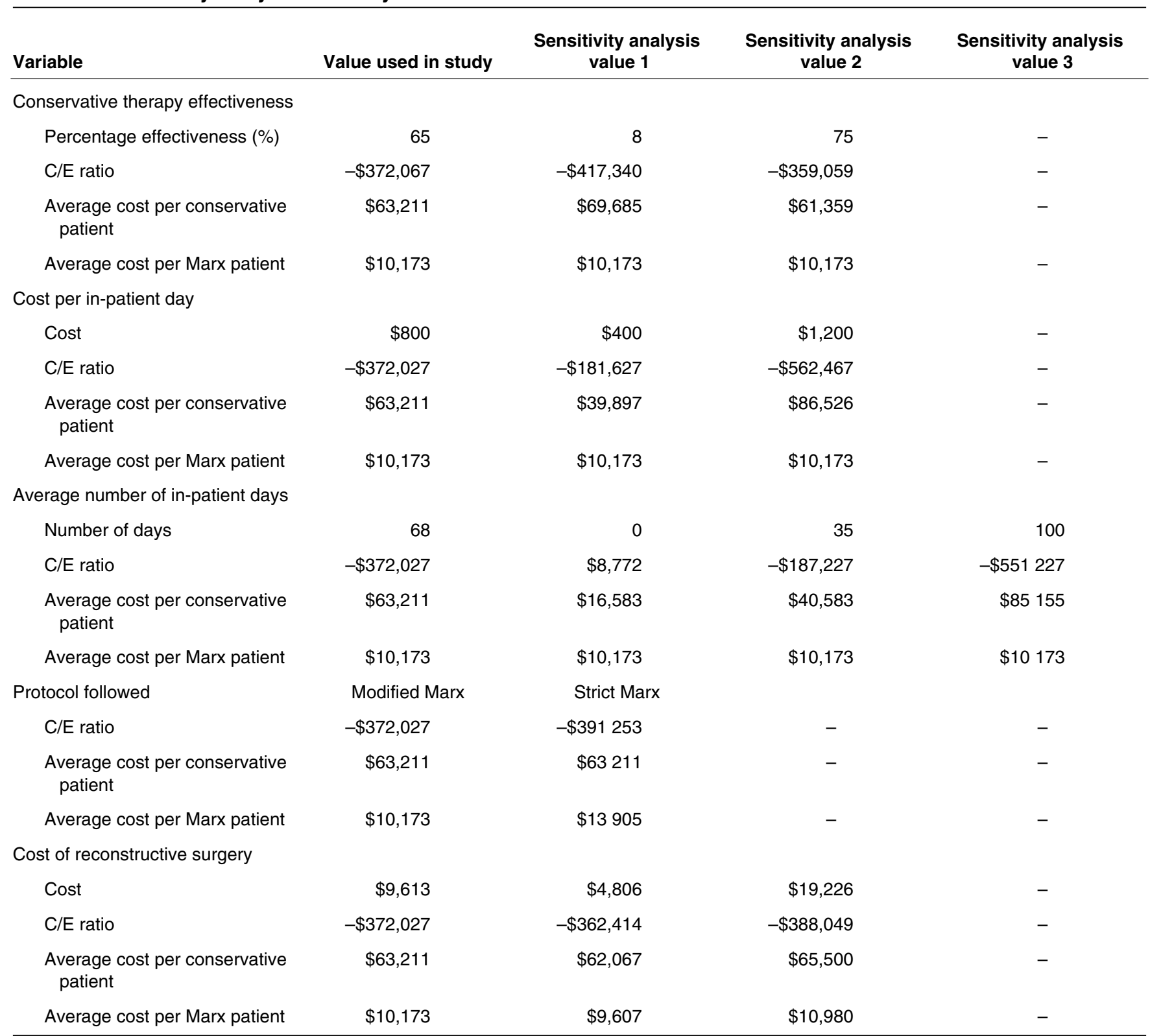

All costs are in 1995 Canadian dollars. C/E Cost effectiveness 
out-patient visits as $\mathrm{HBO}$ protocol patients require dives in the hyperbaric chamber, the lost earnings from these activities would cancel each other out. The difference would thus lie in the number of days spent in the hospital. Because conservative treatment patients spend more time in the hospital than $\mathrm{HBO}$ protocol patients, and conservative therapy was already more expensive, adding lost wages to the cost of treatment would only further increase the cost difference between the two treatments.

The outcome under study in this analysis was complete resolution of disease. However, a number of secondary outcomes should be mentioned. In all 21 patients who underwent the modified HBO protocol, pain reduction occurred by the 10th dive in the hyperbaric chamber. This corresponds to physiologically based neoangiogenesis reported by Davis and Hunt (1), and these patients required fewer analgesics after their 10th dive. Anecdotally, they also experienced longer periods of undisturbed sleep. On the other hand, conservative treatment patients do not experience significant reductions in pain and often become dependent on narcotics (1). Furthermore, dentition was salvaged in $83 \%$ of HBO protocol patients, whereas this number was much lower in the conservative treatment patients.

The results of this study indicate that using the (modified)

\section{REFERENCES}

1. Davis JC, Hunt TK. Problem Wounds: The Role of Oxygen. New York: Elsevier Science, 1988.

2. Morton ME, Simpson W. The management of osteoradionecrosis of the jaw. Br J Oral Maxillofac Surg 1986;24:332-41.

3. Rankow YRM, Weissman B. Osteoradionecrosis of the mandible. Ann Otol Rhinol Laryngol 1971;80:603-11.

4. Meyer I. Infectious diseases of the jaws. J Oral Surg 1970;28:17.

5. Marx RE. Osteoradionecrosis: A new concept of its pathophysiology. J Oral Maxillofac Surg 1983;41:283-8.

6. Harris M. The conservative management of osteoradionecrosis of the mandible with ultrasound therapy. Br J Oral Maxillofac Surg 1992;30:313-8.

7. Daly TE, Drane JB. Management of teeth related to the treatment of oral cancer. National Cancer Conference Proceedings 7. New York: American Cancer Society, 1973.
HBO protocol for the treatment of osteoradionecrosis is less expensive and more effective than conservative treatment. It follows that the HBO protocol should be followed in all cases of osteoradionecrosis treatment.

\section{CONCLUSIONS}

This study evaluated the cost effectiveness of a modified HBO protocol for the treatment of osteoradionecrosis of the mandible compared with conservative therapy. The modified HBO protocol was more effective and less expensive than conservative therapy and, thus, exhibits dominance.

A sensitivity analysis was conducted to determine the effects of changing different assumptions or questionable data. The most significant changes occurred when the number of in-patient days for conservative therapy patients were reduced or eliminated. This indicates that the major cost difference between the two therapies stems from the number of in-patient days of each group.

While this study did not address quality of life issues, patient preferences for different treatment methods or the impact of each treatment on a patient and his or her family, it should be noted that patients who underwent the modified Marx University of Miami protocol enjoyed greater pain reduction and increased sleep.

8. Marx RE, SN Kline. Principles and methods of osseous reconstruction. Int Adv Surg Oncol 1983;6:167-228.

9. Mainous EG, Boyne PJ. Hyperbaric oxygen in total rehabilitation of patients with mandibular osteoradionecrosis. Int J Oral Surg 1974;3:297.

10. Mainous EG, Hart GB. Osteoradionecrosis of the mandible: treatment with hyperbaric oxygen. Arch Otolaryngol 1975;101:173.

11. Marx RE. A new concept in the treatment of osteoradionecrosis. J Oral Maxillofac Surg 1983;41:351-7.

12. Marx RE, Johnson RP, Kline SN. Prevention of osteoradionecrosis: A randomized prospective clinical trial of hyperbaric oxygen vs penicillin. J Am Dent Assoc 1985;111:49-54.

13. Ontario Ministry of Health. Ontario Health Insurance Plan: Schedule of Benefits. Toronto: Queen's Printer, 1995.

14. Drummond MF, Stoddart GL, Torrance GW. Methods for the Economic Evaluation of Health Care Programmes. New York: Oxford University Press Inc, 1987. 